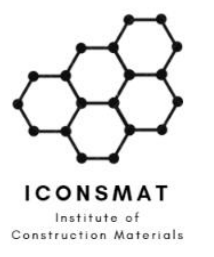

\author{
Content list available at ICONSMAT \\ Journal of Construction Materials
}

Journal homepage: www.iconsmat.com.au/publication

Article history:

Received 20 April 2021

Received in revised form

25 April 2021

Accepted 25 April 2021

Available online

27 April 2021

\title{
Assessment of carbon dioxide separation by amine solutions using electrolyte non-random two-liquid and Peng-Robinson models: Carbon dioxide absorption efficiency
}

\author{
Arash Esmaeili' ${ }^{*}$, Zhibang Liư ${ }^{1}$, Yang Xiang ${ }^{1}$, Jimmy Yun ${ }^{2 *}$, Lei Shao ${ }^{1}$ \\ ${ }^{1}$ Research Center of the Ministry of Education for High Gravity Engineering and Technology, Beijing University of \\ Chemical Technology, Beijing 100029, China \\ ${ }^{2}$ School of Chemical Engineering, The University of New South Wales, Sydney, NSW 2052, Australia \\ *Corresponding authors: Arash Esmaeili (phone: +8613161777098; e-mail: ar.esmaeli@mail.buct.edu.cn); \\ Jimmy Yun (e-mail: jimmy.yun@unsw.edu.au)
}

\begin{abstract}
A high pressure carbon dioxide $\left(\mathrm{CO}_{2}\right)$ absorption from a specific gas in a conventional column has been evaluated by the Aspen HYSYS simulator using a wide range of single absorbents and blended solutions to estimate the outlet $\mathrm{CO}_{2}$ concentration, absorption efficiency and $\mathrm{CO}_{2}$ loading to choose the most proper solution in terms of $\mathrm{CO}_{2}$ capture for environmental concerns. The property package (Acid GasChemical Solvent) which is compatible with all applied solutions for the simulation in this study, estimates the properties based on an electrolyte non-random two-liquid (E-NRTL) model for electrolyte thermodynamics and Peng-Robinson equation of state for the vapor and liquid hydrocarbon phases. Among all the investigated single amines as well as blended solutions, piperazine (PZ) and the mixture of piperazine and monoethanolamine (MEA) have been found as the most effective absorbents respectively for $\mathrm{CO}_{2}$ absorption with high reactivity based on the simulated operational conditions.
\end{abstract}

DOI: 10.36756/JCM.v2.3.10 C2021 Institute of Construction Materials

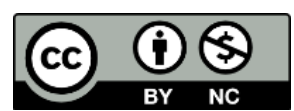

\section{Keywords}

Absorption, amine solutions, Aspen HYSYS, carbon dioxide, simulation. 


\section{Introduction}

The greenhouse gases emission has become one of the most challenging environmental issues during the last few decades and the rising $\mathrm{CO}_{2}$ concentration in the past 200 years has contributed significantly to the global warming phenomena. A wide range of $\mathrm{CO}_{2}$ emissions is directly related to consumption of fossil fuels; therefore, invention and development of efficient processes to reduce capital and operational costs as well as the size of equipment for $\mathrm{CO}_{2}$ capture have attracted wide interest.

Different methods have been developed for $\mathrm{CO}_{2}$ capture based on chemical reactions between $\mathrm{CO}_{2}$ and various types of alkanolamines in both conventional columns and rotating packed beds (RPBs). For example, [1]-[3] studied $\mathrm{CO}_{2}$ absorption by MEA in a conventional column and RPBs, respectively. The most important advantage of absorption is that absorbents can be regenerated by introducing the $\mathrm{CO}_{2}-$ rich absorbents into a stripper where off-gas is removed by rising temperature. The drawbacks of chemical absorption processes include high energy consumption and limited loadings created by heat of reaction and the reaction stoichiometry in addition to the problems of corrosion and degradation with some of the absorbents.

The commonly used absorbents are non-sterically hindered amines (non-SHAs) in aqueous solutions such as MEA and diglycolamine (DGA) as primary amine, diethanolamine (DEA) and diisopropanolamine (DIPA) as secondary amine, methyldiethanolamine (MDEA) and triethanolamine (TEA) as tertiary amine. Sulfinol-D (mixture of DIPA and sulfolane) and Sulfinol-M (mixture of MDEA and sulfolane) as the combination of chemical and physical absorbents have found some significant applications during the last few decades. The blended amine solutions containing SHAs have been also experimented by scientists and industries. For instance, [4] studied $\mathrm{CO}_{2}$ absorption by 2-amino-2methyl-1-propanol (AMP); [5] investigated AMP+MEA in a conventional column; [6] evaluated the blended solution of AMP+PZ; [7] conducted experiments on a number of SHAs; [8] published experimental data for $\mathrm{CO}_{2}$ removal by MEA, DEA, TEA and AMP; [9] and [10] examined $\mathrm{CO}_{2}$ capture by diethylenetriamine (DETA)+PZ and aqueous DETA solution respectively in an RPB.

The absorption of $\mathrm{CO}_{2}$ occurs via a two-step mechanism:

1. the dissolution of $\mathrm{CO}_{2}$ in the aqueous amine solution, and then,

2. the reaction of the weak acid solution with the weakly basic amine.

The first absorption step is controlled by the partial pressure of the $\mathrm{CO}_{2}$ in the gas feed. Amines can be classified according to the number of hydrogen atoms that have been substituted, as primary $\left(\mathrm{R}-\mathrm{NH}_{2}\right.$, where $R$ is a hydrocarbon chain), secondary (R-NH- $\left.R^{\prime}\right)$ or tertiary ( $\left.R^{\prime}-N R-R^{\prime \prime}\right)$ amines [11]. This study investigated the ability of all types of amine solutions as single and blended absorbents to assess their reactivity with $\mathrm{CO}_{2}$ and select the most appropriate one in terms of absorption efficiency.

\section{Chemistry of the reaction between $\mathrm{CO}_{2}$ and Amines}

For primary and secondary amines, such as MEA and DEA, the carbamate formation reaction predominates; this reaction is much faster than the $\mathrm{CO}_{2}$ hydrolysis reaction. The stoichiometry of the carbamate reaction limits the capacity of primary and secondary amines to approximately 0.5 mole of $\mathrm{CO}_{2}$ per mole of amine. However, DEA-based amine processes can also achieve loadings of more than 0.5 mole of $\mathrm{CO}_{2}$ per mole of amine through the partial hydrolysis of carbamate (RNHCOO-) to bicarbonate ( $\mathrm{HCO}-$ ), which regenerates some free amine [11]. Xiao et al. [5] have reviewed the equilibrium reactions of $\mathrm{CO}_{2}$ with both primary and secondary amines: 
Dissociation of water:

$2 \mathrm{H}_{2} \mathrm{O} \rightleftarrows \mathrm{H}_{3} \mathrm{O}^{+}+\mathrm{OH}^{-}$

Hydrolysis and dissociation of dissolved $\mathrm{CO}_{2}$ :

$\mathrm{CO}_{2}+2 \mathrm{H}_{2} \mathrm{O} \rightleftarrows \mathrm{HCO}_{3}^{-}+\mathrm{H}_{3} \mathrm{O}^{+}$

$\mathrm{HCO}_{3}{ }^{-}+\mathrm{H}_{2} \mathrm{O} \rightleftarrows \mathrm{CO}_{3}{ }^{2-}+\mathrm{H}_{3} \mathrm{O}^{+}$

The reaction (R2) is very slow $\left(\mathrm{k}=0.026 \mathrm{~s}^{-1}\right.$ at $25^{\circ} \mathrm{C}$ and may usually be neglected.

Protonation of the amine:

Amine $+\mathrm{H}_{3} \mathrm{O}^{+} \rightleftarrows$ Amine $\mathrm{H}^{+}+\mathrm{H}_{2} \mathrm{O}$

Carbamate formation:

Primary amine:

$\mathrm{RNH}_{2}+\mathrm{HCO}_{3}{ }^{-} \rightleftarrows\left[\mathrm{RNHCOO}^{-}(\right.$carbamate $\left.)+\mathrm{H}_{2} \mathrm{O}\right]$

Secondary amine:

$\mathrm{RNHR}^{\prime}+\mathrm{HCO}_{3}^{-} \rightleftarrows\left[\mathrm{RNR}^{\prime} \mathrm{COO}^{-}(\right.$carbamate $\left.)+\mathrm{H}_{2} \mathrm{O}\right]$

And the subsequent removal of the proton by a base $\mathrm{B}$, which could be an amine, $\mathrm{OH}$ - $\mathrm{or}_{2} \mathrm{O}$, from a zwitterion can be shown as:

$\mathrm{AmineH}^{+} \mathrm{COO}^{-}+\mathrm{B} \rightleftarrows$ AmineCOO$+\mathrm{BH}^{+}$

Tertiary amines, such as MDEA, allow higher amounts of $\mathrm{CO}_{2}$ captured per mole of amine due to a suitable reaction stoichiometry though they present generally a low reaction rate in comparison with primary and secondary amines. This low reaction rate could be associated with a high liquid viscosity that decreases mass transfer rate [12]. The mechanism for the reaction of $\mathrm{CO}_{2}$ with the tertiary amines is as follows [13], [14]:

$\mathrm{R}_{3} \mathrm{~N}+\mathrm{H}_{3} \mathrm{O}^{+} \rightleftarrows \mathrm{R}_{3} \mathrm{NH}++\mathrm{H}_{2} \mathrm{O}$

In the case of a SHA such as AMP, the presence of the methyl group significantly reduces the stability of the carbamate bond which results in the preferred formation of the bicarbonate leading to the particularly high loading capacity of these solvents. SHAs demonstrate certain advantages over conventional non-SHA absorbents for $\mathrm{CO}_{2}$ removal from gases, such as high absorption rate, higher selectivity and resistance to degradation.

When $\mathrm{CO}_{2}$ is absorbed in $\mathrm{PZ}$ solutions, the zwitterion mechanism used for primary and secondary amines can be adopted to explain the formation of carbamate which is regarded as the result of deprotonation of zwitterion generated through the reaction between $\mathrm{CO}_{2}$ and $\mathrm{PZ}$, the following equilibrium chemical reactions with the reactions R1 to R3 take place in the liquid phase [15], [16]:

First and second protonation of PZ:

$\mathrm{PZ}+\mathrm{H}_{3} \mathrm{O}^{+} \rightleftarrows \mathrm{PZH}^{+}+\mathrm{H}_{2} \mathrm{O}$ 
$\mathrm{PZH}^{+}+\mathrm{H}_{3} \mathrm{O}^{+} \rightleftarrows \mathrm{PZH}_{2}{ }^{2+}+\mathrm{H}_{2} \mathrm{O}$

Formation of three carbamate species (PZ carbamate, PZ dicarbamate and protonated PZ carbamate), respectively:

$\mathrm{PZ}+\mathrm{HCO}_{3}{ }^{-} \rightleftarrows \mathrm{PZCOO}^{-}+\mathrm{H}_{2} \mathrm{O}$

$\mathrm{PZCOO}^{-}+\mathrm{HCO}_{3}^{-} \rightleftarrows \mathrm{PZ}\left(\mathrm{COO}^{-}\right)_{2}+\mathrm{H}_{2} \mathrm{O}$

$\mathrm{PZCOO}^{-}+\mathrm{H}_{3} \mathrm{O}^{+} \rightleftarrows \mathrm{PZH}^{+} \mathrm{COO}^{-}+\mathrm{H}_{2} \mathrm{O}$

The theory of mass transfer with chemical reaction can be used to analyze the experimental results. The most significant simplification arises from the pseudo-first-order assumption for kinetics. This assumes the concentration of amine to be constant in the liquid boundary layer. Such simplification transforms the second-order reaction expression of $\mathrm{CO}_{2}$ with an amine to a first-order expression [17]:

$r_{\mathrm{CO2}}=\mathrm{k}_{2, \mathrm{Am}}[\mathrm{Amine}]\left(\left[\mathrm{CO}_{2}\right]-[\mathrm{CO}]^{*}\right)$

$r_{\mathrm{CO} 2}=k_{1}\left(\left[\mathrm{CO}_{2}\right]-\left[\mathrm{CO}_{2}\right]^{*}\right)$

where $\mathrm{k}_{2, \mathrm{Am}}\left(\mathrm{m}^{3} / \mathrm{kmol} . \mathrm{s}\right)$ is the second-order reaction rate constant; [Amine] and $\left[\mathrm{CO}_{2}\right]$ are amine and $\mathrm{CO}_{2}$ concentration $\left(\mathrm{kmol} / \mathrm{m}^{2} . \mathrm{s}\right)$ respectively, $\left[\mathrm{CO}_{2}\right]^{*}$ is the equilibrium concentration of $\mathrm{CO}_{2} ; \mathrm{k} 1(1 / \mathrm{s})$ is the rate constant for the pseudo-first-order reaction and defined as:

$k_{1}=k_{2, A m} \cdot[$ Amine $]$

The reaction kinetics of $\mathrm{CO}_{2}$ with MEA has been studied extensively in the literature [1]. Regardless of the experimental techniques and conditions, all the data for the reaction of $\mathrm{CO}_{2}$ with MEA are in very good agreement. The first-order reaction rate for MEA was suggested as follows for the temperature range of $4.8-35^{\circ} \mathrm{C}$ and MEA concentration of $0.0152-0.177 \mathrm{M} \mathrm{[18]:}$

$r_{\text {CO2-MEA }}=k_{2, \text { MEA }}[M E A][C O 2]$

$\log k_{2, M E A}=10.99-2152 / T$

The reaction rate of $\mathrm{CO}_{2}$ absorption into a blended amine solution can be considered as a rapid pseudofirst-order reversible reaction and expressed as [19]:

$N_{\mathrm{CO} 2}=\frac{\sqrt{D_{\mathrm{CO} 2}\left(k_{2,15 t} \text { Amine } \cdot C_{2,1 \text { st Amine }}+k_{\left.2,2 n d \text { Amine } \cdot C_{2,2 n d} \text { Amine }\right)}\right.}}{H_{\mathrm{CO} 2}}\left(P_{\mathrm{CO} 2, \text { bulk }}-P *_{\mathrm{CO} 2}\right)$

\section{Simulation of $\mathrm{CO}_{2}$ absorption by amine solutions}

The simulation of $\mathrm{CO}_{2}$ absorption from a specific gas was conducted by different kinds of absorbents in a conventional column with 10 trays using Aspen HYSYS simulator to estimate the outlet $\mathrm{CO}_{2}$ concentration, absorption efficiency and $\mathrm{CO}_{2}$ loading so as to choose the most proper absorbent solution in terms of $\mathrm{CO}_{2}$ absorption rate. Therefore, the studies of required parameters, data and correlations such as Gibbs free energy, binary interaction coefficients and etc., have been avoided by application of the property package of Acid Gas-Chemical Solvent and the main focus of interest is absorption efficiency. The schematic of absorption process is depicted in Fig. 1. 


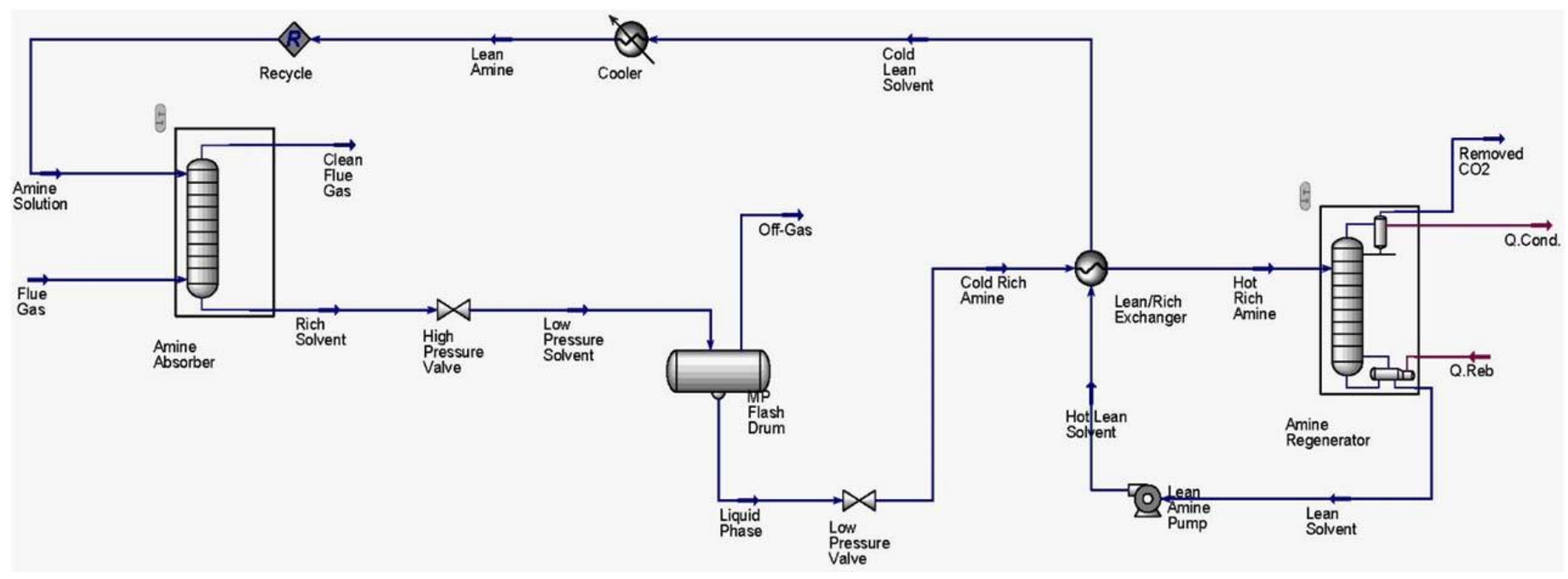

Figure 1 - The schematic CO2 absorption process by using amine solution in Aspen HYSYS

Nine single amine absorbents and 15 blended amine solutions have been investigated. The single amine solutions include PZ, MEA, DGA, DIPA, DEA, MDEA, TEA, Sulfinol- D (30 wt\% DIPA+15\%Sulfolane) and Sulfinol-M (30wt\% MDEA+15\%Sulfolane) while the latter two are considered as a mixture of chemical and physical absorbents. All these solutions were introduced into the column with a concentration of $45 \mathrm{wt} \%$ and flow rate of $850 \mathrm{kmol} / \mathrm{hr}$. The appointed concentration of $45 \mathrm{wt} \%$ makes the model able to be converged in Aspen HYSYS by all chosen single absorbents. The blended amine solutions are divided into two parts: the first part constitutes PZ+MEA, PZ+DGA, PZ+ MDEA, PZ+DEA, PZ+TEA, MEA+DGA, MEA+MDEA, MEA+DEA and MEA+TEA in contact with the gas separately with a concentration of 30 wt\% and flow rate of $500 \mathrm{kmol} / \mathrm{hr}$, the second part comprises DIPA+PZ, DIPA+MEA, DIPA+DGA, DIPA+DEA, DIPA+MDEA and DIPA+TEA which were introduced into the column separately with a concentration of $30 \mathrm{wt} \%$ and flow rate of $850 \mathrm{kmol} / \mathrm{hr}$. The second part adopted a higher flow rate because the blended DIPA solutions with a flow rate of $500 \mathrm{kmol} / \mathrm{hr}$ could not be converged by Aspen HYSYS in the column including ten trays with the specific gas composition. In this study, absorption efficiency of single absorbents is not compared with that of the blended solutions. Some of these blended solutions, such as PZ+MEA [20], [21] and PZ+MDEA [22-24] have been studied in the literature.

The molar composition of the gas was $27.36 \% \mathrm{CO}_{2}, 34.73 \% \mathrm{CO}, 37.49 \% \mathrm{H}_{2}, 0.19 \% \mathrm{CH}_{4}$ and $0.23 \% \mathrm{H}_{2} \mathrm{O}$. The gas was introduced into the column in the conditions $35^{\circ} \mathrm{C}, 58.5 \mathrm{barg}$ and $96.8 \mathrm{kmol} / \mathrm{hr}$ while all solutions were introduced into the column in $45^{\circ} \mathrm{C}$, 59.0 barg to investigate $\mathrm{CO}_{2}$ absorption. The Acid Gas-Chemical Solvent property package is based on the Electrolyte NRTL model for electrolyte thermodynamics [23] and Peng-Robinson equation of state for vapor phase and liquid hydrocarbon phase properties. This property package is based on extensive research and development in rate-based, simulation of chemical absorption process and molecular thermodynamics models for aqueous amine solutions, it contains the parameters identified from regression of thermodynamic and physical property data such as VLE and heat of absorption for amine solutions. It is highly recommended the rate-based model is used instead of equilibrium model for the simulation of $\mathrm{CO}_{2}$ absorption, the characteristic that distinguishes this model from the equilibrium is the accuracy of results in such a way that the rate-based model considers the following parameters in order to predict the performance of $\mathrm{CO}_{2}$ absorption process and the required energy of solvent regeneration: mass transfer correlation, thermodynamics and kinetics 
model, heat transfer correlation, physicochemical properties (density, viscosity, diffusivity, surface tension, and etc.) and flow model.

The correlations used to simulate the $\mathrm{CO}_{2}$ absorption are illustrated in Table 1 . The investigation and comparison of $\mathrm{CO}_{2}$ absorption capability with a wide range of amine absorbents has not been conducted in previous studies.

Table 1 - The model and correlations used for simulation of $\mathrm{CO}_{2}$ absorption by amine solution

\begin{tabular}{cc} 
Model approach & Used correlation \\
Flow model & V-plug \\
Liquid density & Clarke model \\
Liquid viscosity & Jones-Dole model \\
Liquid surface tension & Onsager-Samaras model \\
Binary diffusivity & Nernst-Hartley model \\
Therman conductivity & Riedel model \\
Mass transfer & AlCHE model \\
Heat transfer coefficient & Chilton and Colburn \\
Liquid film resistance & Discrxn model \\
Vapor fil resistance & Film model \\
\hline
\end{tabular}

\section{A.Comparison of single amine and blended amine solutions}

For the nine single amine solutions with $45 \mathrm{wt} \%$ and $850 \mathrm{kmol} / \mathrm{hr}$ by considering no lean- $\mathrm{CO}_{2}$ loading, the following order was obtained from the strongest absorbent to the weakest based on the kinetics parameters which are shown in Tables 2 and 3 for zwitterion and protonated amine formation (reactions $5,6,8$ ) as well as electrolytes formation (reactions $2,11,12$ ) respectively. This order clearly shows the extent of chemical absorption and reactivity. These results are generally compatible with the previous experimental studies on some of amine absorbents. For instance, [10], [17], [25] and [26] and have carried out experiments and calculated the second order reaction rates for some of single and blended alkanolamines applied in this study and acquired almost the same order and their results verify the model used in this study.

$$
\mathrm{PZ}>\mathrm{MEA}>\mathrm{DGA}>\mathrm{DIPA}>\mathrm{DEA}>\text { Sulfinol }-\mathrm{D}>\text { Sulfinol }-\mathrm{M}>\mathrm{MDEA}>\mathrm{TEA}
$$

Table 2 - Kinetic parameters of $\mathrm{CO}_{2}$ absorption by primary, secondary, and tertiary amines

\begin{tabular}{|c|c|c|c|}
\hline Solvent & Type of reaction & k & $\mathrm{E}_{\mathrm{a}}(\mathrm{cal} / \mathrm{mol})$ \\
\hline \multirow{2}{*}{ MEA [27] } & forward & $9.77 E+10$ & 9855.8 \\
\hline & backward & $2.18 \mathrm{E}+18$ & 14138.4 \\
\hline DGA [27] & forward & $1.94 \mathrm{E}+15$ & 15813 \\
\hline
\end{tabular}




\begin{tabular}{|c|c|c|c|}
\hline & backward & $3.0 \mathrm{E}+26$ & 25287 \\
\hline \multirow{2}{*}{ DIPA [27] } & forward & $4.09 \mathrm{E}+9$ & 9563.1 \\
\cline { 2 - 4 } & backward & $2.16 \mathrm{E}+19$ & 15021 \\
\hline \multirow{2}{*}{ DEA [27] } & forward & $6.48 \mathrm{E}+16$ & 5072 \\
\cline { 2 - 4 } & backward & $1.43 \mathrm{E}+17$ & 11497 \\
\hline \multirow{2}{*}{ MDEA [28] } & forward & $6.85 \mathrm{E}+10$ & 9029 \\
\cline { 2 - 4 } & backward & $6.62 \mathrm{E}+17$ & 22131 \\
\hline \multirow{2}{*}{ TEA [18] } & forward & $2.02 \mathrm{E}+11$ & 8837 \\
\cline { 2 - 4 } & backward & $5.02 \mathrm{E}+18$ & 22288 \\
\hline
\end{tabular}

The $\mathrm{CO}_{2}$ removal by $\mathrm{PZ}$ resulted in the off-gas with only $61.2 \mathrm{ppm} \mathrm{CO} 2$ in outlet as this absorbent has the highest reaction rate with $\mathrm{CO}_{2}$, while such absorption by TEA brought about an outlet $\mathrm{CO}_{2}$ to concentration of $22184.8 \mathrm{ppm}$ as this solvent is subject to the lowest reaction rate in the same concentration and operational conditions. The reason can be attributed to a higher reactivity resulting from the higher reaction heat of $\mathrm{PZ}$ with $\mathrm{CO}_{2}$.

Table 3 - Kinetics parameters of bicarbonate and species of PZ carbamate formation

\begin{tabular}{|c|c|c|c|}
\hline \multicolumn{1}{|c}{ Solvent } & Type of reaction & $k$ & $E_{a}$ (cal/mol) \\
\hline \multirow{2}{*}{ Bicarbonate } & forward & $1.33 \mathrm{E}+17$ & 13249 \\
\cline { 2 - 4 } & backward & $6.63 \mathrm{E}+16$ & 25656 \\
\hline \multirow{2}{*}{ PZ carbamate } & forward & $1.70 \mathrm{E}+10$ & 319 \\
\cline { 2 - 4 } & backward & $3.40 \mathrm{E}+23$ & 14160 \\
\hline \multirow{2}{*}{ PZ bicarbamate } & forward & $1.04 \mathrm{E}+14$ & 8038.3 \\
\cline { 2 - 4 } & backward & $3.20 \mathrm{E}+20$ & 8692 \\
\hline
\end{tabular}

This order can be illustrated as $\mathrm{CO}_{2}$ absorption efficiency which is depicted in Fig. 2. Efficiency term , $\eta$, is defined as the percentage of $\mathrm{CO}_{2}$ removed from the inlet gas stream of the column by absorption process and expressed as [25]:

$\eta=\left[1-\left(\frac{y_{\mathrm{CO} 2, \mathrm{out}}}{1-y_{\mathrm{CO} 2, \text { out }}}\right)\left(\frac{1-y_{\mathrm{CO} 2 \text {,in }}}{y_{\mathrm{CO}, \text { in }}}\right)\right] \times 100=\left[1-\frac{y_{\mathrm{CO} 2, \mathrm{out}}}{y_{\mathrm{CO} 2 \text {, in }}}\right] \times 100$

Consequently, $\mathrm{PZ}$ possesses the highest efficiency of $99.98 \%$ for $\mathrm{CO}_{2}$ removal while TEA has the lowest efficiency of $93.98 \%$; in other words, $\mathrm{PZ}$ is able to absorb more $\mathrm{CO}_{2}$ because of carbamate formation and higher reaction heat; nevertheless, TEA has slower reaction rate due to lowest order of magnitude in its second order reaction rate constant and indirect reaction with $\mathrm{CO}_{2}$. 


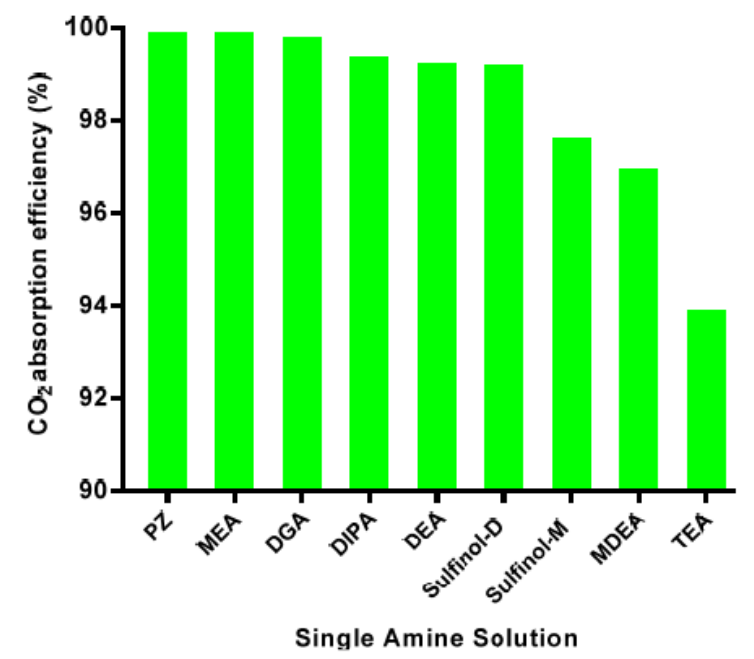

Figure $2-\mathrm{CO}_{2}$ removal efficiency by $45 \mathrm{wt} \%$ single amine solutions with flow rate of $850 \mathrm{kmol} / \mathrm{hr}$
Aroonwilas et al. [25] studied five different single amine solutions as MEA, DEA, AMP, DIPA and MDEA with a constant concentration $3.0 \mathrm{kmol} / \mathrm{m}^{3}$ for $\mathrm{CO}_{2}$ removal. According to their studies with the mentioned absorbents, MEA has obtained the highest amount of $\mathrm{CO}_{2}$ absorption while MDEA has attained the lowest in terms of $\mathrm{CO}_{2}$ absorption efficiency as well as reaction heat which is similar to the achieved results in this study.

The order of $\mathrm{CO}_{2}$ loading $(\alpha)$ (as molar flow of absorbed $\mathrm{CO}_{2}$ to molar flow of amine solvent) in the nine absorbents is shown as follows and the detailed data are given in Fig. 3. It is clear that TEA reached the highest $\mathrm{CO}_{2}$ loading in 0.326 on account of higher reaction stoichiometry, while the minimum $\mathrm{CO}_{2}$ loading was achieved by MEA in 0.160 owing to having the lowest equilibrium solubility and the fact that its maximum absorption capacity is limited to 0.5 mole $\mathrm{CO}_{2}$ per mole MEA. Some of these absorbents have been experimentally investigated by [29].

TEA $>$ DIPA $>$ Sulfinol $-\mathrm{D}>$ Sulfinol $-\mathrm{M}>\mathrm{MDE}>\mathrm{DGA}>\mathrm{DEA}>\mathrm{PZ}>\mathrm{MEA}$

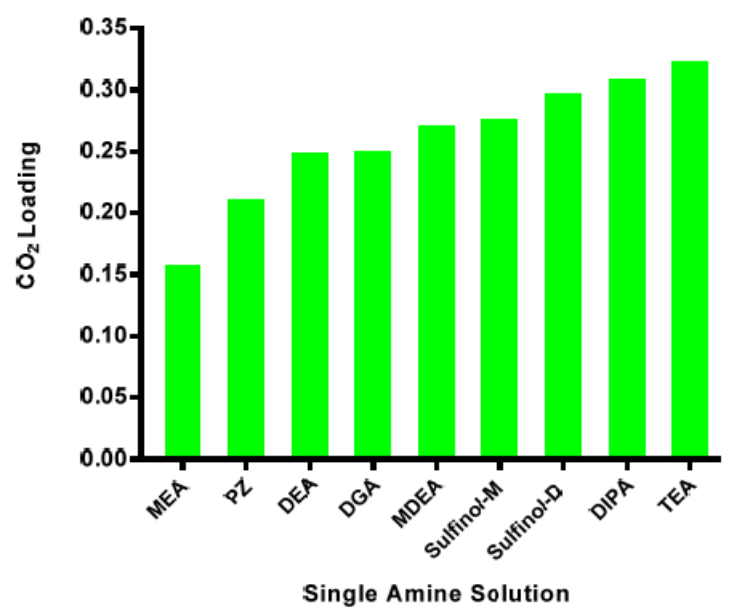

Figure $3-\mathrm{CO}_{2}$ loading in $45 \mathrm{wt} \%$ single amine solutions with flow rate of $850 \mathrm{kmol} / \mathrm{hr}$
The second-order reaction rate constant between amine and $\mathrm{CO}_{2}$ is independent of absorbent concentration and it is only a function of temperature, so it can be concluded that the reaction between them is a rapid pseudo-first-order reversible reaction [22]. The second order reaction rate constant for PZ [22], DEA [30], DGA [31], MDEA [14] and TEA [13] are as follows, respectively, the values of which are indicated for the mentioned amine absorbents within 305-335 K in Fig. 4. 


$$
k_{2, P Z}\left[m^{3} / k m o l . s\right]=4.0 \times 10^{10} \cdot \exp \left(\frac{-4059.4}{T}\right)
$$

$$
\log k_{2, D E A}\left[m^{3} / k m o l . s\right]=10.4493-\frac{2274.5}{T}
$$

$k_{2, D G A}\left[m^{3} / k m o l . s\right]=6.66 \times 10^{3} \cdot \exp \left(-4823.1\left(\frac{1}{T}-\frac{1}{298}\right)\right)$

$k_{2, M D E A}\left[m^{3} / k m o l . s\right]=5.86 \times 10^{6} \cdot \exp \left(\frac{-3984}{T}\right)$

$$
k_{2, T E A}\left[\mathrm{~m}^{3} / \mathrm{kmol} . \mathrm{s}\right]=3.311 \times 10^{10} \cdot \exp \left(\frac{-4089}{T}\right)
$$

The ability of an absorbent to remove $\mathrm{CO}_{2}$ is dictated by its equilibrium solubility as well as mass transfer and chemical kinetics characteristics [17]. Being a cyclic symmetric diamine, each mole of PZ can theoretically absorb two moles of $\mathrm{CO}_{2}$ and $\mathrm{PZ}$ may favor rapid formation of the carbamates.

The apparent second-order rate constant of $\mathrm{PZ}$ has been found to be an order at least higher than that of conventional alkanolamines such as MEA which is shown in Figs. 4 and 5 based on logarithmic-scale. Most of $\mathrm{CO}_{2}$ is absorbed from the middle to the bottom of column owing to higher driving force between gas and absorbent, the mole fraction of $\mathrm{CO}_{2}$ in the liquid phase has reached to $6.79 \times 10^{-6}$ by $\mathrm{PZ}$ on the top of the column while the minimum value of that is about $1.05 \times 10^{-4}$ using DIPA which represents two order of magnitudes difference. In other words, PZ has been able to obtain the similar solubility on tray no.7 from the bottom and there has been less $\mathrm{CO}_{2}$ concentration on the upper stages to be absorbed but such solubility has attained with a slighter slop by DIPA on tray no.10 which proves that $\mathrm{CO}_{2}$ absorption by DIPA requires an absorber with higher number of stages and height than that of by PZ to achieve the same solubility. The order shown in Fig. 5 is identical to [26] on MEA, DEA and TEA. Whereas $\mathrm{PZ}$ is effective in promoting the rate of $\mathrm{CO}_{2}$ absorption even at its low concentrations in blend with other amine absorbents, it is known as an activator or promoter in industrial processes.

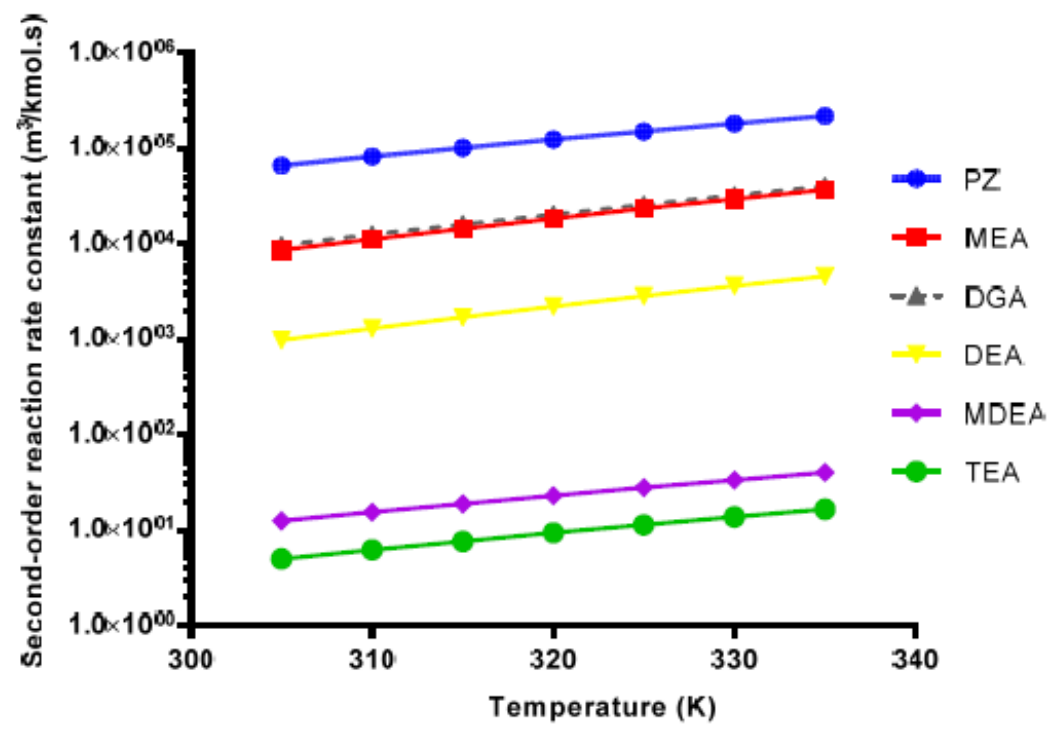

Figure 4 - The estimated values of second-order reaction rate constant for amine absorbents 


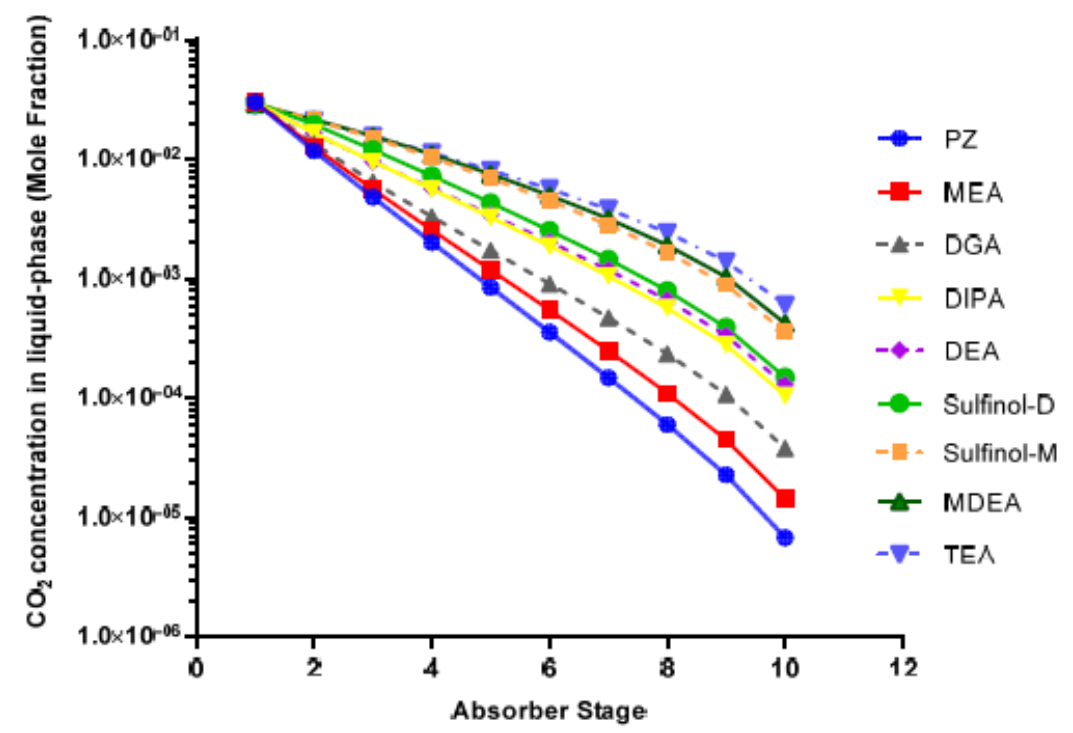

Figure 5 - The values of absorbed $\mathrm{CO}_{2}$ in $45 \mathrm{wt} \%$ single amine solutions with flow rate of $85 \mathrm{kmol} / \mathrm{hr}$

For the blended solutions with $30 \mathrm{wt} \%$ and $500 \mathrm{kmol} / \mathrm{hr}$, the following order demonstrates $\mathrm{CO}_{2}$ absorption efficiency of nine different mixtures, and in consequence, solution of $\mathrm{PZ}$ and MEA possesses the fastest reaction with $\mathrm{CO}_{2}$ which can be observed in Figs. 6 and 7. Some of these solutions have been studied before, e.g. [25] reported that MEA+MDEA has much more tendency to absorb $\mathrm{CO}_{2}$ than DEA+MDEA, and our results confirms that the mixture of DEA and MDEA is subject to the lowest absorption efficiency with the outlet $\mathrm{CO}_{2}$ concentration varying from 19,618 ppm to $14,220 \mathrm{ppm}$ while DEA concentrations varied between $5 \mathrm{wt} \%$ and $25 \mathrm{wt} \%$ :

$P Z+M E A>P Z+D G A>P Z+M D E A>P Z+D E A>P Z+T E A>M E A+D G A>M E A+M D E A>M E A+D E A>$ $M E A+T E A$

Fig. 6 shows the effect of the blended amine solutions with various $\mathrm{PZ}$ concentrations on $\mathrm{CO}_{2}$ removal. PZ was employed as an activator and mixed with five different absorbents to form 30 wt\% solutions while the concentration of $\mathrm{PZ}$ in each solution varied from $5 \mathrm{wt} \%$ to $25 \mathrm{wt} \%$. Exceptionally, TEA solution was evaluated from $10 \mathrm{wt} \%$ due to lack of sufficient reactivity in the solution of $5 \mathrm{wt} \% \mathrm{PZ}+25 \mathrm{wt} \% \mathrm{TEA}$ with $\mathrm{CO}_{2}$ to be converged by this model. It is clear that $\mathrm{CO}_{2}$ removal was improved by increasing PZ concentration, particularly for the amines with slower reaction rate such as DEA and TEA. After the gas was treated by the solution of $\mathrm{PZ}+\mathrm{TEA}$, the outlet $\mathrm{CO}_{2}$ concentration declined by $93 \%$ with an increasing $\mathrm{PZ}$ concentration from $10 \mathrm{wt} \%$ to $25 \mathrm{wt} \%$, while there was only $42 \%$ decrease in the outlet $\mathrm{CO}_{2}$ concentration for the solution of PZ+MEA with $25 \mathrm{wt} \% \mathrm{PZ}$ in comparison with that of $5 \mathrm{wt} \% \mathrm{PZ}$, in such a way the outlet $\mathrm{CO}_{2}$ concentration by the solution of $5 \mathrm{wt} \% \mathrm{PZ}+25 \mathrm{wt} \% \mathrm{MEA}$ is around $421 \mathrm{ppm}$ which is comparatively lower than the same $\mathrm{PZ}$ concentration blended with other absorbents. Regardless of $\mathrm{PZ}+\mathrm{MEA}$ solution, $\mathrm{PZ}+\mathrm{DGA}$ exhibited a higher $\mathrm{CO}_{2}$ absorption than other mixtures except the case of 5 $w t \% \mathrm{PZ}+25 \mathrm{wt} \% \mathrm{DGA}$ in which the outlet $\mathrm{CO}_{2}$ concentration reached $1450 \mathrm{ppm}$ compared to 1070.1 by 5 wt\% PZ+25 wt\% MDEA. TEA demonstrated the lowest absorption ability and the outlet $\mathrm{CO}_{2}$ concentration was as high as $4412 \mathrm{ppm}$ in the solution of $10 \mathrm{wt} \% \mathrm{TEA}+20 \mathrm{wt} \% \mathrm{PZ}$. Similarly, $\mathrm{CO}_{2}$ removal was simulated by the $30 \mathrm{wt} \%$ blended amine solutions with MEA concentration of $5 \mathrm{wt} \%, 10 \mathrm{wt} \%, 15$ 
wt\%, $20 \mathrm{wt} \%$ and $25 \mathrm{wt} \%$ and the results are shown in Fig. 7, which illustrates that $\mathrm{CO}_{2}$ removal performance of MEA with other amines followed the same order as that of $\mathrm{PZ}$ with other amines although the outlet $\mathrm{CO}_{2}$ concentration was 6-8 times higher for the solutions with MEA than those with $\mathrm{PZ}$ at the same concentration. The values of $\mathrm{CO}_{2}$ absorbed by the solutions of MEA+DGA, MEA+MDEA and MEA+DEA were close to each other in the lowest concentration of MEA (5 wt\%). These results suggest that the MEA does not influence much at lowest concentration and the effect of those three absorbents (DGA, MDEA and DEA) predominates, while MEA affects $\mathrm{CO}_{2}$ absorption significantly at higher concentrations (from $10 \mathrm{wt} \%$ ) and somehow overshadows the effect of the other compounds in the solution.

Fig. 8 depicts $\mathrm{CO}_{2}$ removal by the blended amine solutions with different concentrations of DIPA as a secondary amine. Contrary to the mixture of $\mathrm{PZ}$ with other absorbents that brought about a descending outlet $\mathrm{CO}_{2}$ concentration with increasing PZ mass ratio, the blended solutions with DIPA demonstrate up or down trends with increasing DIPA concentration depending on their reaction rates with $\mathrm{CO}_{2}$ as well as $\mathrm{CO}_{2}$ solubility in these absorbents. Considering the fact that PZ, MEA and DGA have higher reactivity with $\mathrm{CO}_{2}$ than DIPA, increasing DIPA concentration affected $\mathrm{CO}_{2}$ absorption reversely and led to a rise in the outlet $\mathrm{CO}_{2}$ concentration as much as $2.78,4.86$ and 2.15 times, respectively. On the other side, a rise in DIPA concentration in the mixtures of DIPA+DEA caused a slight increase in the outlet $\mathrm{CO}_{2}$ concentration as 1.11 times because DIPA more promotes $\mathrm{CO}_{2}$ loading than the reaction rate compared with DEA and finally, brought on higher $\mathrm{CO}_{2}$ concentration in the outlet gas which has a good consistency with the previous literature [25].

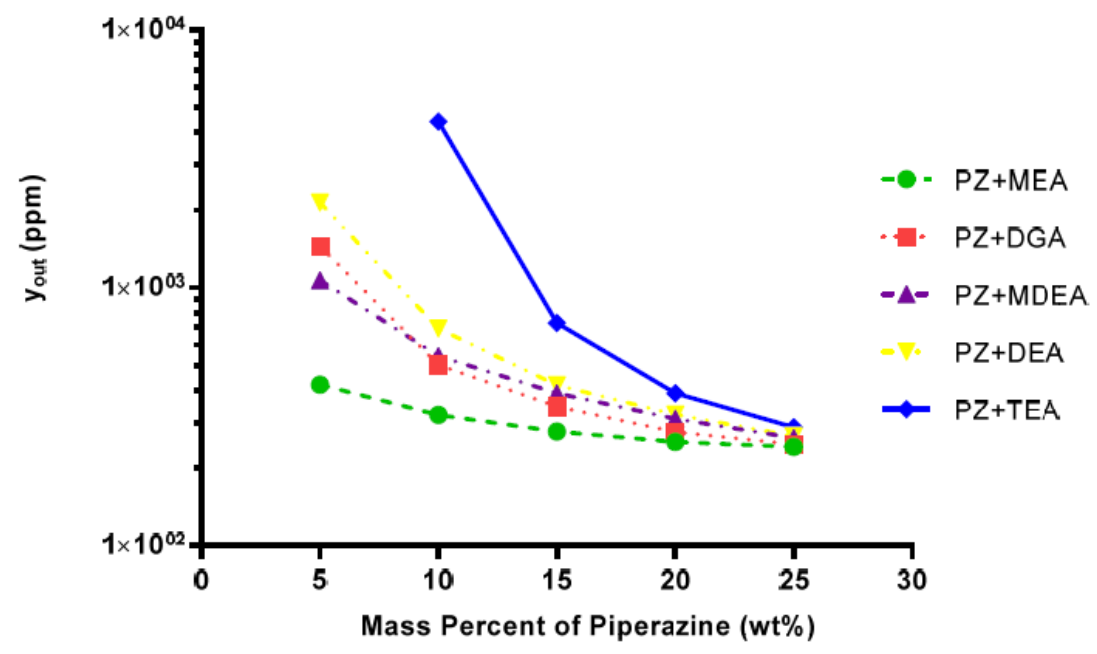

Figure 6 - Comparison of $\mathrm{CO}_{2}$ absorption by different $30 \mathrm{wt} \%$ blended solutions mixed with PZ. 


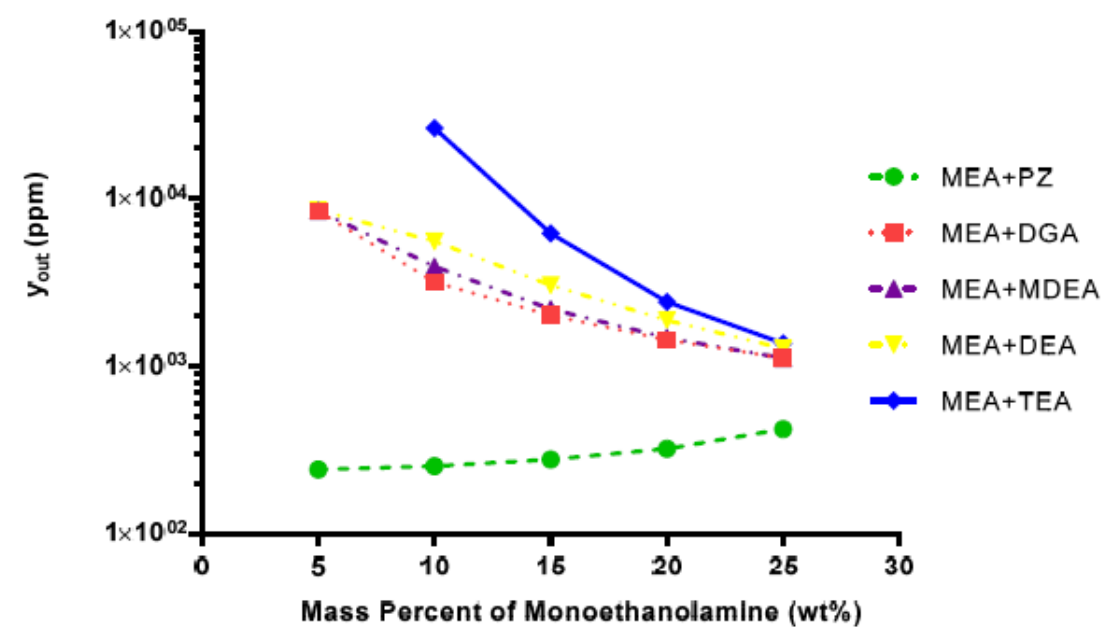

Figure 7 - Comparison of $\mathrm{CO}_{2}$ absorption by different 30 wt\% blended solutions mixed with MEA.

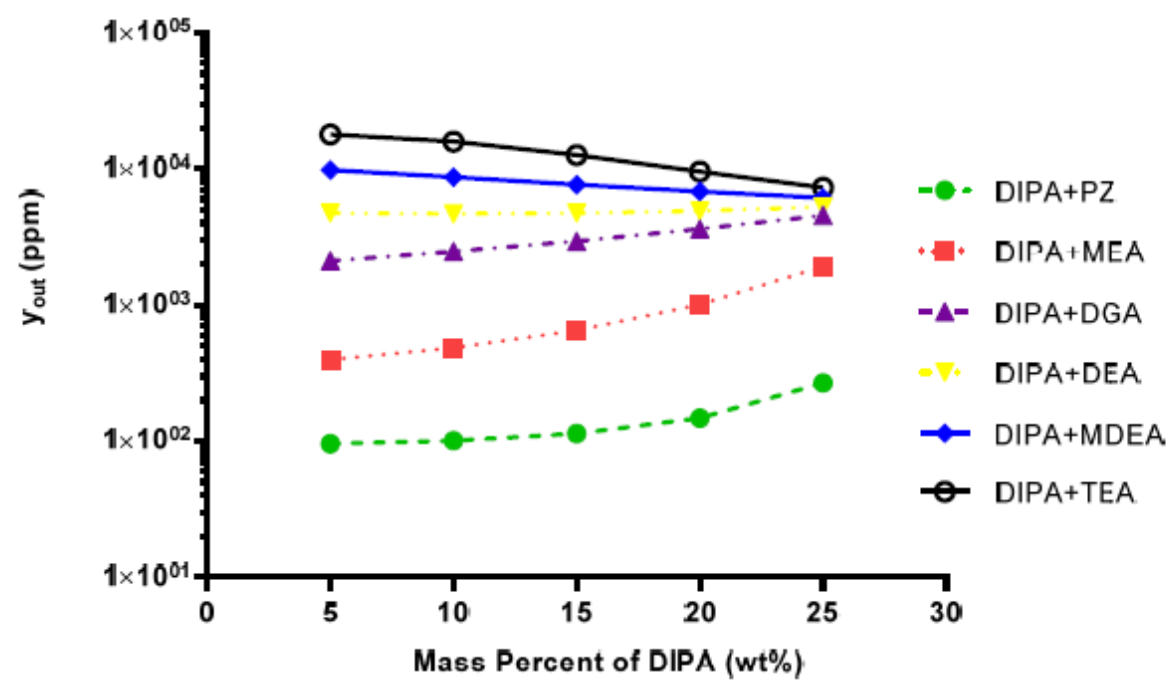

Figure 8 - Comparison of $\mathrm{CO}_{2}$ absorption by different $30 \mathrm{wt} \%$ blended solutions mixed with DIPA

In DIPA+MDEA and DIPA+TEA solutions, both controlling parameters of higher reactivity of DIPA than MDEA and TEA in addition to higher solubility of $\mathrm{CO}_{2}$ in DIPA compared with MDEA led to the decrease in the outlet $\mathrm{CO}_{2}$ concentration by $37.6 \%$ and $59.5 \%$, respectively. Therefore, DIPA in mixture with tertiary amine solvents makes more efficient blended solutions than that of with other type of amine because it promotes the slow reaction rate of tertiary amine absorbents as an activator in such a way that DIPA worked effectively on the top trays of the column and then higher solubility of $\mathrm{CO}_{2}$ in MDEA or TEA caused $\mathrm{CO}_{2}$ reduction on the bottom trays and consequently in the outlet gas. These trends are in good agreement with [25] which shows a mixed kinetic/thermodynamic competition in a blended solution between two reactive components (MEA or DEA and MDEA). Based on their experiments, promoters play a key role in controlling absorption rate in low $\mathrm{CO}_{2}$ loadings because they react with $\mathrm{CO}_{2}$ in a faster rate than other amine component to form very stable carbamate components. As $\mathrm{CO}_{2}$ loading is enhanced, more $\mathrm{CO}_{2}$ is converted to promoter carbamate resulting in reduction of unreacted promoter to unreacted tertiary amine ratio. Consequently, tertiary amine obtains its role in estimation of $\mathrm{CO}_{2}$ absorption rate. When blended amines are used, promoters probably act as primary reactant to 
absorb $\mathrm{CO}_{2}$ on upper section of column while the other amine component controls absorption on lower sections.

\section{B. Investigation of operational parameters on $\mathrm{CO}_{2}$ absorption by $\mathrm{PZ}+\mathrm{MEA}$}

In order to investigate the effect of operational conditions on $\mathrm{CO}_{2}$ absorption in the column, five parameters, e.g. solution temperature, gas temperature, solution flow rate, gas flow rate and lean- $\mathrm{CO}_{2}$ loading for the strongest solution, $25 \mathrm{wt} \% \mathrm{PZ}+5 \mathrm{wt} \% \mathrm{MEA}$, were studied, while the effect of streams temperature was assessed simultaneously and that of streams flow rate was also examined together. Pressure and flow rate of the gas and liquid streams are $58.5 \mathrm{barg}$ and $96.8 \mathrm{kmol} / \mathrm{hr}$ as well as $59.0 \mathrm{barg}$ and $500 \mathrm{kmol} / \mathrm{hr}$, respectively.

Fig. 9 represents the effect of $\mathrm{PZ}+\mathrm{MEA}$ solution temperature on $\mathrm{CO}_{2}$ absorption. It is clear that rising solution temperature resulted in a higher $\mathrm{CO}_{2}$ removal because high temperature can enhance the reaction rate between the amine solution and $\mathrm{CO}_{2}$ and thus increased liquid-side mass transfer coefficient despite the fact that higher temperature causes lower $\mathrm{CO}_{2}$ solubility in the solution. The effect of gas temperature is shown in Fig. 10, which indicates that increasing gas temperature at a certain amine solution temperature did not affect $\mathrm{CO}_{2}$ absorption, obviously because the main mass transfer resistance is in liquid film even if gas temperature increase brings about a rising in gas-side mass transfer coefficient. This observation is in agreement with other studies [32]. The temperature over $60{ }^{\circ} \mathrm{C}$ is not a good choice for amine solutions based on the operating conditions and recommendations in literature [10], and thus the investigation was performed up to this temperature.

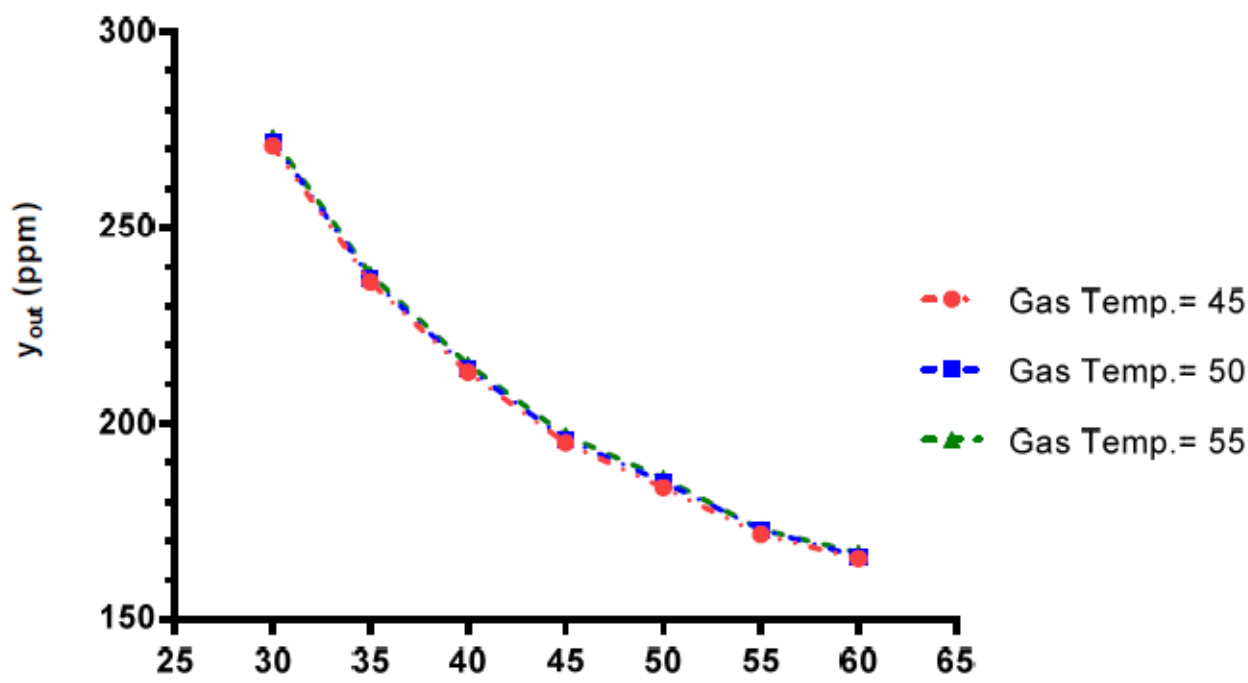

PZ+MEA Solution Temperature $\left({ }^{\circ} \mathrm{C}\right)$

Figure 9 - Outlet $\mathrm{CO}_{2}$ concentration vs $\mathrm{PZ}+\mathrm{MEA}$ solution temperature with three different gas temperatures. 


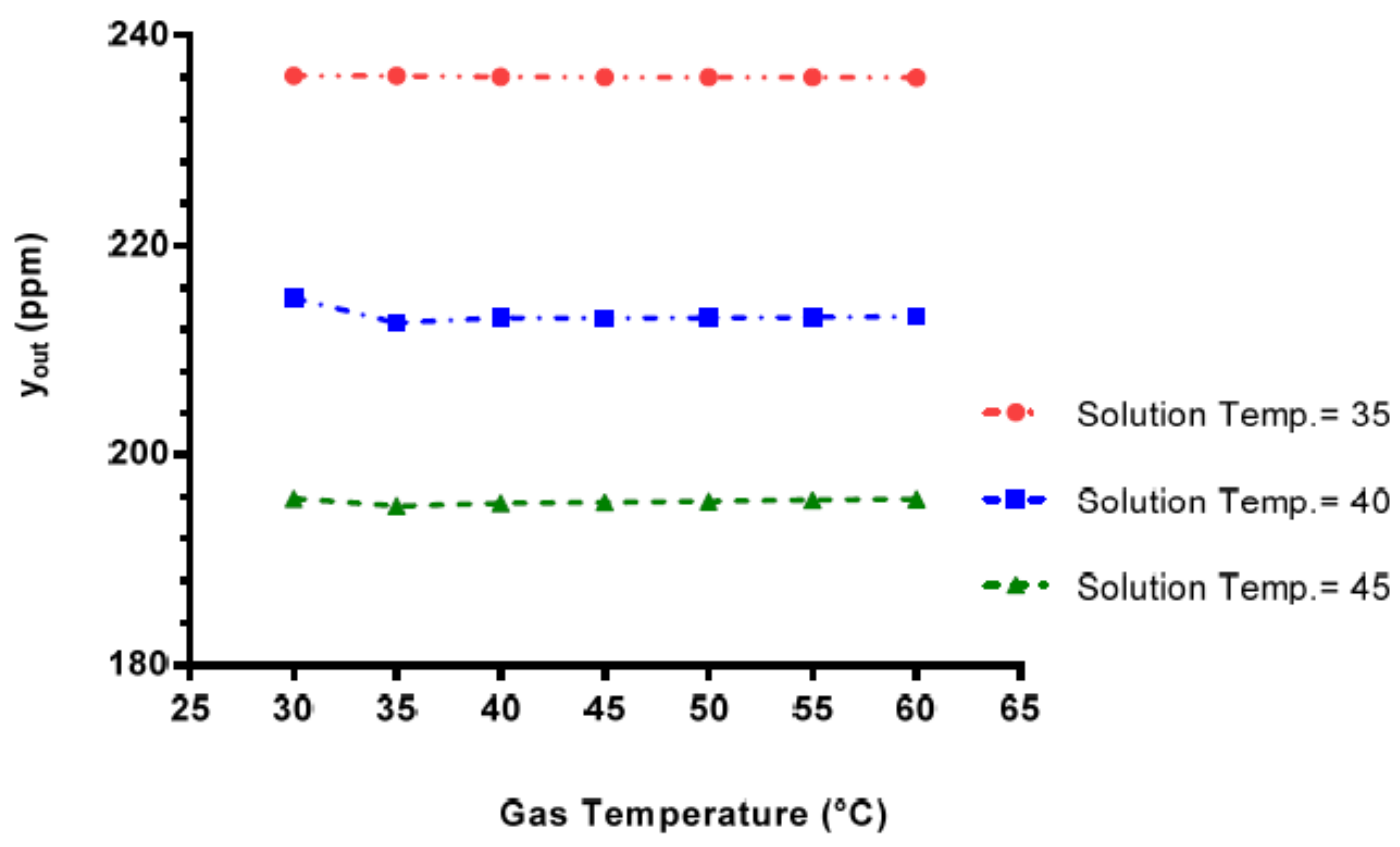

Figure 10 - Outlet $\mathrm{CO}_{2}$ concentration vs. gas temperature with three different $\mathrm{PZ}+\mathrm{MEA}$ solution temperatures

The influence of gas flow rate on $\mathrm{CO}_{2}$ absorption is illustrated in Fig. 11, which shows that higher gas flow rate at a fixed liquid flow rate led to higher outlet $\mathrm{CO}_{2}$ concentration while the inlet temperature of the gas and absorbent were $35^{\circ} \mathrm{C}$ and $45^{\circ} \mathrm{C}$, respectively. A rising gas flow rate from $90 \mathrm{kmol} / \mathrm{hr}$ to $130 \mathrm{kmol} / \mathrm{hr}$ not only results in higher $\mathrm{CO}_{2}$ amount per unit time in the column but shortens gas-liquid contact time, thereby causing a lower $\mathrm{CO}_{2}$ absorption efficiency. Figs. 11 and 12 also indicate that rising $\mathrm{PZ}+\mathrm{MEA}$ solution flow rate assisted to decrease the outlet $\mathrm{CO}_{2}$ concentration as a result of higher liquidside and overall mass transfer coefficients. Furthermore, Fig. 12 clearly indicates that there was negligible difference in the value of absorbed $\mathrm{CO}_{2}$ with various gas flow rates when PZ+MEA solution flow rate increased from $600 \mathrm{kmol} / \mathrm{hr}$ to $900 \mathrm{kmol} / \mathrm{hr}$. Consequently, the flow rate of $600 \mathrm{kmol} / \mathrm{hr}$ can be chosen as the minimum required flow of the absorbent where the operating line and the equilibrium curve meet each other.

Fig. 13 illustrates the variation of rich- $\mathrm{CO}_{2}$ loading (the amount of absorbed $\mathrm{CO}_{2}$ in rich amine) versus lean- $\mathrm{CO}_{2}$ loading (the amount of remained $\mathrm{CO}_{2}$ in lean amine after regeneration) in different solution flow rates. The rich- $\mathrm{CO}_{2}$ loading increases with rising lean- $\mathrm{CO}_{2}$ loading up to a specific point depends on the value of solution flow rate, i.e. increasing the amount of $\mathrm{CO}_{2}$ in lean solution has led to more absorbed $\mathrm{CO}_{2}$ in rich amine solutions but the maximum solubility is subject to the flow rate so that the minimum flow rate is $600 \mathrm{kmol} / \mathrm{hr}$ to achieve rich- $\mathrm{CO}_{2}$ loading equal to 1.0 and the lower flow rates were not able to reach this amount of rich loading. On the other hand, the rich- $\mathrm{CO}_{2}$ loading has declined with increasing solution flow rate in a constant lean- $\mathrm{CO}_{2}$ loading; this trend is in good agreement with the similar work [21]. Fig. 14 depicts the values of outlet $\mathrm{CO}_{2}$ in the off-gas with the variation of lean$\mathrm{CO}_{2}$ loading which has increased in various solution flow rates in such a way that there is no much difference between the values of outlet $\mathrm{CO}_{2}$ for the flow rates of $600 \mathrm{kmol} / \mathrm{hr}$ and $650 \mathrm{kmol} / \mathrm{hr}$ from the rich- $\mathrm{CO}_{2}$ loading of 0.35 . 


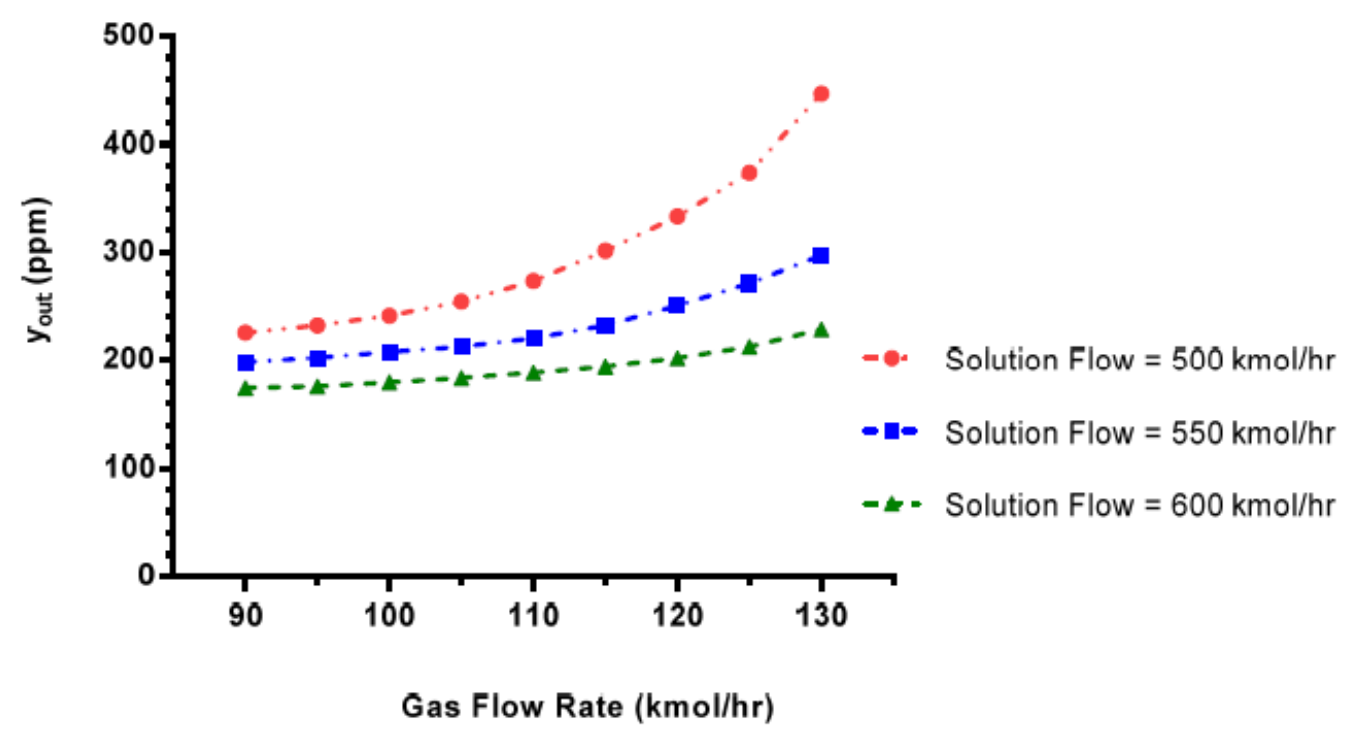

Figure 11 - Outlet $\mathrm{CO}_{2}$ concentration vs. gas flow rate with three different $\mathrm{PZ}+\mathrm{MEA}$ solution flow rates.

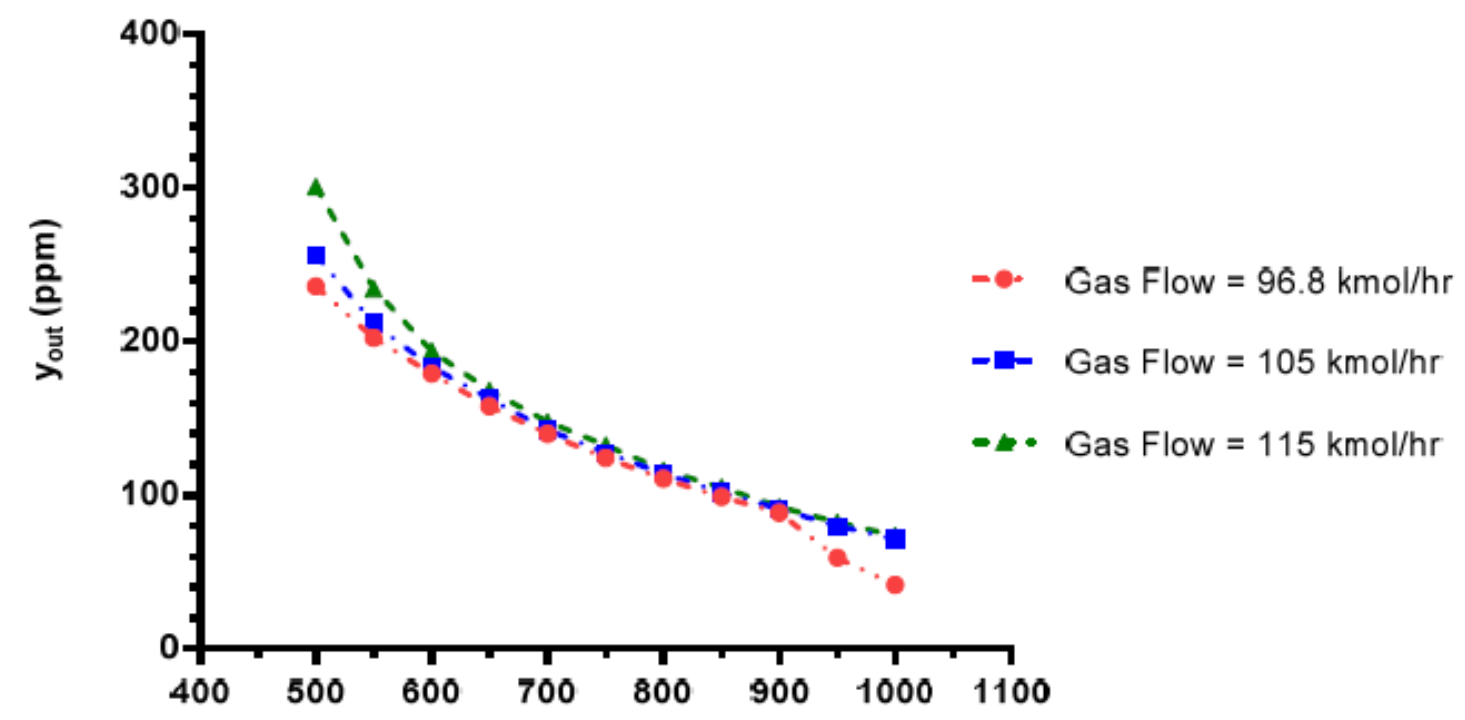

PZ+MEA Solution Flow Rate (kmol/hr)

Figure 12 - Outlet $\mathrm{CO}_{2}$ concentration vs. PZ+MEA solution flow rate with three different gas flow rates. 


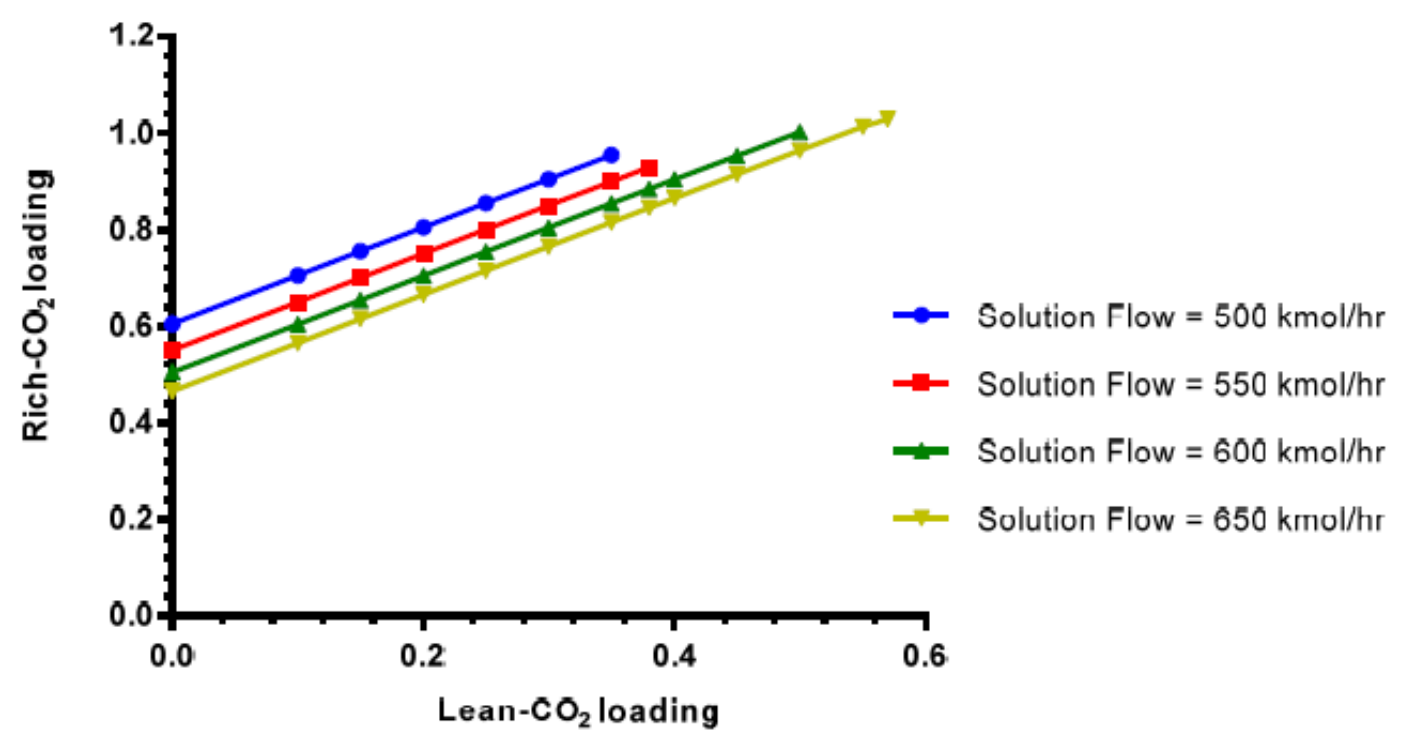

Figure 13 - Rich- $\mathrm{CO}_{2}$ loading of $\mathrm{PZ}+\mathrm{MEA}$ solution vs. lean- $\mathrm{CO}_{2}$ loading with various solution flow rates.

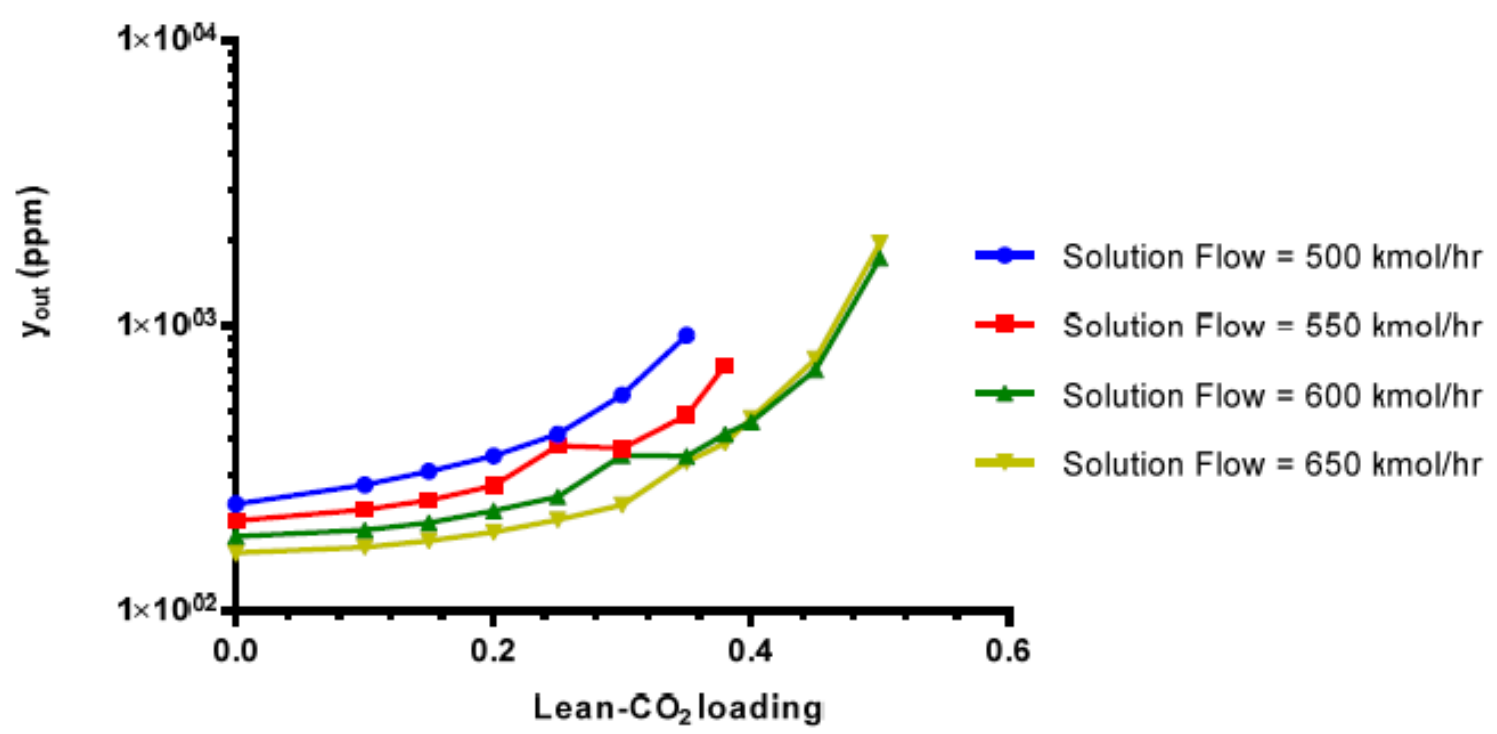

Figure 14 - Outlet $\mathrm{CO}_{2}$ concentration vs. lean- $\mathrm{CO}_{2}$ loading with various solution flow rates.

The applications of $\mathrm{CO}_{2}$ capturing technologies expand to, recently, construction industry as well [3336]. Proposals had been made to install pilot plants on cement factories which are known to be a major cause of $\mathrm{CO}_{2}$ emission. Commonwealth Scientific and industrial research Organization (CSIRO) had invested huge amounts in the research and developments associated with this particular topic. However, the economic challenges on the way to a proper commercialized capturing plant is still upheld [36-43]. 


\section{Conclusion}

The conventional absorption column module in Aspen HYSYS was used to investigate $\mathrm{CO}_{2}$ removal efficiency of a wide range of single and blended aqueous amine solutions, which include PZ, MEA, DEA, MDEA, DIPA, TEA, DGA, Sulfinol-D and Sulfinol-M as well as PZ+MEA, PZ+DGA, PZ+MDEA, PZ+DEA, PZ+TEA, MEA+DGA, MEA+MDEA, MEA+DEA and MEA+TEA; in addition to DIPA+PZ, DIPA+MEA, DIPA+DGA, DIPA+DEA, DIPA+MDEA and DIPA+TEA. It was found that PZ and the mixture of PZ and MEA were the most appropriate solutions for $\mathrm{CO}_{2}$ absorption among the single amine absorbents and blended solutions owing to the higher order of magnitude in second-order reaction rate constant, fastest reaction rate and highest efficiency, while TEA exhibited the maximum $\mathrm{CO}_{2}$ loading on account of its higher equilibrium capacity. Furthermore, increasing the amine solution temperature improved $\mathrm{CO}_{2}$ removal while variation of gas temperature had a negligible effect on $\mathrm{CO}_{2}$ absorption. An increase in the gas flow rate or decrease in the PZ+MEA solution flow rate resulted in an obvious rise in outlet $\mathrm{CO}_{2}$ concentration. It was observed that the outlet $\mathrm{CO}_{2}$ concentration varied a little with the increase of the gas flow rate from $96.8 \mathrm{kmol} / \mathrm{hr}$ to $115 \mathrm{kmol} / \mathrm{hr}$ at the $\mathrm{PZ}+\mathrm{MEA}$ solution flow rate in the range of $600 \mathrm{kmol} / \mathrm{hr}$ to $900 \mathrm{kmol} / \mathrm{hr}$. Moreover, enhancing lean $-\mathrm{CO}_{2}$ loading has led to rising the values of $\mathrm{CO}_{2}$ in the outlet gas and rich solvent, the results of Figs. 12-14 were useful to estimate the minimum required solution flow rate in this model. This work can provide guideline for the selection of suitable absorbents in $\mathrm{CO}_{2}$ capture.

\section{Acknowledgment}

This work was financially supported by the National Natural Science Foundation of China (No. 21676008).

\section{Nomenclature}

\section{Symbols used}

$\begin{array}{lll}{[\mathrm{Amine}]} & {\left[\mathrm{kmol} \mathrm{m}^{-3}\right]} & \text { Concentration of amine } \\ {\left[\mathrm{CO}_{2}\right]} & {\left[\mathrm{kmol} \mathrm{m}^{-3}\right]} & \mathrm{CO}_{2} \text { concentration in the liquid bulk } \\ {\left[\mathrm{CO}_{2}\right]^{*}} & {\left[\mathrm{kmol} \mathrm{m}^{-3}\right]} & \text { Equilibrium concentration of } \mathrm{CO}_{2} \\ \mathrm{~B} & {[-]} & \text { Base } \\ \mathrm{C} & {\left[\mathrm{kmol} \mathrm{m}^{-3}\right]} & \text { Concentration } \\ D_{\mathrm{G}, L} & {\left[\mathrm{~m}^{2} \mathrm{~s}^{-1}\right]} & \text { Diffusivity of gas in liquid phase } \\ E_{a} & {\left[\mathrm{cal} \mathrm{mol}{ }^{-1}\right]} & \text { Activation energy } \\ \mathrm{N} & {\left[\mathrm{kmol} \mathrm{m}^{-2} \mathrm{~s}^{-1}\right]} & \text { Molar mass-transfer flux } \\ \mathrm{P}_{\mathrm{CO} 2, \text { bulk }} & {[\mathrm{Pa}]} & \text { Partial pressure of } \mathrm{CO}_{2} \text { in the gas bulk } \\ \mathrm{P}^{*} \mathrm{CO}_{\mathrm{CO}} & {[\mathrm{Pa}]} & \text { Equilibrium partial pressure of } \mathrm{CO}_{2} \\ r & {\left[\mathrm{kmol} \mathrm{m} \mathrm{s}^{-1}\right]} & \text { Reaction rate } \\ T & {[\mathrm{~K}]} & \text { Absolute temperature } \\ y & {[-]} & \text { Mole fraction of } \mathrm{CO}_{2} \\ \mathrm{Y} & {[-]} & \text { Molar ration of } \mathrm{CO}_{2}[\mathrm{y} /(1-\mathrm{y})]\end{array}$




\section{Greek symbols}

$\alpha$

$\eta$

\section{Subscripts}

Am

In

Out

\section{Abbreviations}

$\mathrm{RNH}_{2}$

RNHR'

$\mathrm{R}^{\prime} N R R^{\prime \prime}$
[-]

[\%]
$\mathrm{CO}_{2}$ loading

Absorption efficiency of $\mathrm{CO}_{2}$
Amine

Inlet

outlet

Primary amine

Secondary amine

Tertiary amine

\section{References}

[1] Hikita, H.; Asai, S.; Katsu, Y.; Ikuno, S. Absorption of carbon dioxide into aqueous monoethanolamine solutions, AICHE J. 1979, 25, 793-800.

[2] Lin, C.; Liu, W.; Tan, C. Removal of carbon dioxide by absorption in a rotating packed bed, Ind. Eng. Chem. Res. 2003, 42, 2381-2386.

[3] Jassim, M. S.; Rochelle, G.; Eimer, D.; Ramshaw, C. Carbon dioxide absorption and desorption in aqueous monoethanolamine solutions in a rotating packed bed, Ind. Eng. Chem. Res. 2007, $46,2823-2833$.

[4] Aroonwilas, A.; Tontiwachwuthikul, P. High-efficiency structured packing for CO2 separation using 2-amino-2-methyl-1-propanol (AMP), J. Sep. Purif. Technol. 1997, 12, 67-79.

[5] Xiao, J.; Li, C.; Li, M. Kinetics of absorption of carbon dioxide into aqueous solutions of 2-amino2-methyl-1-propanol + monoethanolamine, J. Chem. Eng. Sci. 2000, 55, 161-175.

[6] Seo, D. J.; Hong, W. H. Effect of piperazine on the kinetics of carbon dioxide with aqueous solutions of 2-amino-2-methyl-1-propanol, Ind. Eng. Chem. Res. 2000, 39, 2062-2067.

[7] Bougie, F.; Iliuta, M. C. Analysis of regeneration of sterically hindered alkanolamines aqueous solutions with and without activator, J. Chem. Eng. Sci. 2010, 65, 4746-4750.

[8] Kim, Y. E.; Lim, J. A.; Jeong, S. K.; Yoon, Y. I.; Bae, S. T. Comparison of carbon dioxide absorption in aqueous MEA, DEA, TEA, and AMP solutions, Bull. Korean Chem. Soc. 2013, 34, 783-787.

[9] Yu, C.; Cheng, H.; Tan, C. CO2 capture by alkanolamine solutions containing diethylenetriamine and piperazine in a rotating packed bed, Int. J. Greenhouse Gas Control, 2012, 9, 136-147. 
[10] Sheng, M.; Xie, C.; Zeng, X.; Sun, B.; Zhang, L. Intensification of CO2 capture using aqueous diethylenetriamine (DETA) solution from simulated gas in a rotating packed bed, Fuel, 2018, $234,1518-1527$.

[11] Rufford, T. E.; Smart, S.; Watson, G. C. Y.; Graham, B. F. The removal of CO2 and N2 from natural gas: a review of conventional and emerging process technologies, J. Pet. Sci. Eng. 2012, 94-95, 123-154.

[12] Garcia-Abuin, A.; Gomez-Diaz, D.; Navaza, J. M.; Rumbo, A.; Carbon dioxide capture with tertiary amines. Absorption rate and reaction mechanism, J. Taiwan Inst. Chem. Eng. 2017, 80, 356-362.

[13] Sotelo, J. L.; Benitez, F. J.; Beltran-Heredia, J.; Rodriguez, C. Absorption of carbon dioxide into aqueous solutions of triethanolamine, AICHE J. 1990, 36 (8), 1263-1266.

[14] Xu, G.; Zhang, C.; Qin, S.; Wang, Y. Kinetics study of absorption of carbon dioxide into solutions of activated methyldiethanolamine, Ind. Eng. Chem. Res. 1992, 31, 921-927.

[15] Ermatchkov, V.; Kamps, A. P. S.; Speyer, D.; Maurer, G. Solubility of carbon dioxide in aqueous solutions of piperazine in the low gas loading region, J. Chem. Eng. Data, 2006, 51, 1788-1796.

[16] Bougie, F.; Iliuta, M. C. CO2 absorption in aqueous piperazine solutions: experimental study and modeling, J. Chem. Eng. Data, 2011, 56, 1547- 1554.

[17] Bishnoi, S.; Rochelle, G. T. Absorption of carbon dioxide into aqueous piperazine: reaction kinetics, mass transfer and solubility, J. Chem. Eng. Sci. 2000, 55, 5531-5543.

[18] Hikita, H.; Asai, S.; Ishikawa, H.; Honda, M. The kinetics of reactions of carbon dioxide with monoethanolamine, diethanolamine and triethanolamine by a rapid mixing method, Chem. Eng. J. 1977, 13, 7- 12.

[19] Zhang, X.; Zhang, C.; Liu, Y. Kinetics of absorption of CO2 into aqueous solution of MDEA blended with DEA, Ind. Eng. Chem. Res. 2002, 41, 1135-1141.

[20] Dugas, R.; Rochelle, G. Absorption and desorption rates of carbon dioxide with monoethanolamine and piperazine, Energy Procedia, 2009, 1, 1163-1169.

[21] Dugas, R. E.; Rochelle, G. CO2 absorption rate into concentrated aqueous monoethanolamine and piperazine, J. Chem. Eng. Data, 2011, 56, 2187-2195.

[22] Zhang, X.; Zhang, C.; Qin, S.; Zheng, Z. A kinetics study on the absorption of carbon dioxide into a mixed aqueous solution of methyldiethanolamine and piperazine, Ind. Eng. Chem. 2001, 40, 3785- 3791.

[23] Bishnoi, S.; Rochelle, G. T. Absorption of carbon dioxide in aqueous piperazine/methyldiethanolamine, AICHE J. 2002, 48, 2788-2799.

[24] Samanta, A.; Roy, S.; Bandyopadhyay, S. S. Physical solubility and diffusivity of N2O and CO2 in aqueous solutions of piperazine and ( $\mathrm{N}$ - methyldiethanolamine + piperazine), J. Chem. Eng. Data, 2007, 52, 1381-1385. 
[25] Aroonwilas, A.; Veawab, A. Characterization and comparison of the CO2 absorption performance into single and blended alkanolamines in a packed column, Ind. Eng. Chem. Res. $2004,43,2228-2237$.

[26] Rahimi, A.; Tavakoli, T.; Saadat, A.; Niksiar, A. Modeling and experimental study of CO2 removal by alkanolamines in a packed bed, Sep. Sci. Technol. 2014, 49, 317-328.

[27] Borhani, T. N. G.; Akbari, V.; Hamid, M. K. A.; Manan, A. M. Rate- based simulation and comparison various promoters for $\mathrm{CO} 2$ capture in industrial DEA-promoted potassium carbonate absorption unit, J. Ind. Eng. Chem. 2015, 22, 306-316.

[28] Hemmati, A.; Farahzad, R.; Surendar, A.; Aminahmadi, B.; Validation of mass transfer and liquid holdup correlations for $\mathrm{CO} 2$ absorption process with methyldiethanolamine solvent and piperazine as an activator, Process Saf. Environ. Protection. 2019, 126, 214-222.

[29] Wang, Y. W.; Xu, S.; Otto, F. D., Mather, A. E. Solubility of N2O in alkanolamines and in mixed solvnets, Chem. Eng. J. 1992, 48, 31-40.

[30] Blauwhoff, P. M. M.; Versteeg, G. F.; van Swaaij, W. P. M. A study on the reaction between CO2 and alkanolamines in aqueous solutions, Chem. Eng. Sci. 1983, 38, 1411-1429.

[31] Al-Juaied, M.; Rochelle, G. T. Absorption of CO2 in aqueous diglycolamine, Ind. Eng. Chem. Res. 2006, 45, 2473-2482.

[32] Lin, C.; Lin, Y.; Tan, C. Evaluation of alkanolamine solutions for carbon dioxide removal in crossflow rotating packed bed, J. Hazard. Mater. 2010, 175, 344-351.

[33] F. Sartipi, "A brief critical view on the carbon-conditioning of recycled aggregate using pressure chamber," Journal of Construction Materials, vol. 2, pp. 1-4, 2020, doi: https://doi.org/10.36756/JCM.v2.1.4.

[34] A. Gharizadeh, F. Sartipi, E. Ayoubi, and A. Severino, "The chemical reactor design configuration of $\mathrm{CO} 2$ concrete green solution," Journal of Construction Materials, vol. 1, pp. 2-5, 2020, doi: https://doi.org/10.36756/JCM.v1.2.5.

[35] J. Luliano, A. Singh, and F. Sartipi, "Political-economical evaluation of CO2 capture in Australian building sector," Journal of Construction Materials, vol. 1, pp. 3-2, 2020, doi: https://doi.org/10.36756/JCM.v1.3.2.

[36] A. Todhunter, M. Crowley, F. Sartipi, and K. Jegendran, "Use of the by-products of postcombustion carbon capture in concrete production: Australian case study," Journal of Construction Materials, 2019.

[37] P. Feron et al., "Seawater Desalination with an Amine-based CO2-Capture Process," Available at SSRN 3821327, 2021.

[38] A. Kiani, K. Jiang, and P. Feron, "Techno-economic assessment for $\mathrm{CO} 2$ capture from air using a conventional liquid-based absorption process," Frontiers in Energy Research, vol. 8, p. 92, 2020.

[39] B. Garg, N. Haque, A. Cousins, P. Pearson, T. V. Verheyen, and P. H. Feron, "Techno-economic evaluation of amine-reclamation technologies and combined $\mathrm{CO} 2 / \mathrm{SO} 2$ capture for Australian coal-fired plants," International Journal of Greenhouse Gas Control, vol. 98, p. 103065, 2020. 
[40] F. Sartipi, "Diffusion of Innovation Theory in the Realm of Environmental Construction," Journal of Construction Materials, vol. 1, pp. 4-2, 2020, doi: https://doi.org/10.36756/JCM.v1.3.2.

[41] F. Sartipi, "Organizational structure of construction entities based on the cooperative game theory," Journal of Construction Materials, vol. 1, no. 2, 2020, doi: https://doi.org/10.36756/JCM.v1.3.3

[42] A. Kandiri, F. Sartipi, and M. Kioumarsi, "Predicting Compressive Strength of Concrete Containing Recycled Aggregate Using Modified ANN with Different Optimization Algorithms," Applied Sciences, vol. 11, no. 2, p. 485, 2021, doi: https://doi.org/10.3390/app11020485.

[43] F. Sartipi, "Publicizing construction firms by cryptocurrency," Journal of Construction Materials, vol. 2, pp. 3-1, 2021, doi: https://doi.org/10.36756/JCM.v2.3.1. 